\title{
Pioglitazone does not enhance the effectiveness of lifestyle modification in preventing conversion of impaired glucose tolerance to diabetes in Asian Indians: results of the Indian Diabetes Prevention Programme-2 (IDPP-2)
}

\author{
A. Ramachandran $\cdot$ C. Snehalatha $\cdot$ S. Mary $\cdot$ \\ S. Selvam • C. K. S. Kumar • A. C. Seeli • \\ A. S. Shetty
}

Received: 23 October 2008 / Accepted: 9 February 2009/Published online: 10 March 2009

(C) Springer-Verlag 2009

\begin{abstract}
Aims/hypothesis The objective of this prevention programme was to study whether combining pioglitazone with lifestyle modification would enhance the efficacy of lifestyle modification in preventing type 2 diabetes in Asian Indians with impaired glucose tolerance.

Methods In a community-based, placebo-controlled 3 year prospective study, 407 participants with impaired glucose tolerance (mean age $45.3 \pm 6.2$ years, mean BMI 25.9 \pm $3.3 \mathrm{~kg} / \mathrm{m}^{2}$ ) were sequentially grouped to receive either: lifestyle modification plus pioglitazone, $30 \mathrm{mg}(n=204)$ or lifestyle modification plus placebo $(n=203)$. The participants and investigators were blinded to the assignment. The primary outcome was development of diabetes.

Results At baseline, both groups had similar demographic, anthropometric and biochemical characteristics. At year 3, the response rate was $90.2 \%$. The cumulative incidence of diabetes was $29.8 \%$ with pioglitazone and $31.6 \%$ with placebo (unadjusted HR 1.084 [95\% CI 0.753-1.560], $p=0.665$ ). Normoglycaemia was achieved in $40.9 \%$ and $32.3 \%$ of participants receiving pioglitazone and placebo, respectively
\end{abstract}

A. Ramachandran $\cdot$ C. Snehalatha $\cdot$ S. Mary $\cdot$ S. Selvam $\cdot$

C. K. S. Kumar'A. C. Seeli $\cdot$ A. S. Shetty

India Diabetes Research Foundation,

Egmore,

Chennai, India

A. Ramachandran $(\bowtie) \cdot$ C. Snehalatha $\cdot$ S. Mary $\cdot$ S. Selvam $\cdot$

C. K. S. Kumar • A. C. Seeli $\cdot$ A. S. Shetty

Dr A. Ramachandran's Diabetes Hospitals,

28 Marshalls Road, Egmore,

Chennai 600 008, India

e-mail: ramachandran@vsnl.com $(p=0.109)$. In pioglitazone group, two deaths and two nonfatal hospitalisations occurred due to cardiac problems; in the placebo group there were two occurrences of cardiac disease. Conclusions/interpretation Despite good adherence to lifestyle modification and drug therapy, no additional effect of pioglitazone was seen above that achieved with placebo. The effectiveness of the intervention in both groups was comparable with that of lifestyle modification alone, as reported from the Indian Diabetes Prevention Programme-1. The results are at variance with studies that showed significant relative risk reduction in conversion to diabetes with pioglitazone in Americans with IGT. An ethnicity-related difference in the action of pioglitazone in non-diabetic participants may be one explanation.

Trial registration: ClinicalTrials.gov NCT00276497

Funding: This study was funded by the India Diabetes Research Foundation

Keywords Carbohydrate metabolism · Epidemiology . Nutrition and diet - Oral pharmacological agents .

Prediction and prevention of type 2 diabetes mellitus
Abbreviations
ACT NOW Actos Now for Prevention of Diabetes
DREAM Diabetes Reduction Assessment With
GDM $\quad$ Ramipril and Rosiglitazone M
HOMA-IR Homeostasis model assessment for insulin resistance
IDPP Indian Diabetes Prevention Programme
IGT Impaired glucose tolerance 


\section{Introduction}

The efficacy of lifestyle modification in preventing the deterioration of impaired glucose tolerance (IGT) to type 2 diabetes is proven [1-5]. Insulin sensitisers such as metfor$\min [3,4]$ and the glitazones $[6,7]$ have also been useful in the primary prevention of diabetes in people with IGT and in women with a history of gestational diabetes (GDM) [8, 9], in different ethnic groups. Results of the Actos Now for Prevention of Diabetes (ACT NOW) study, presented in the 68th Annual Meeting of the American Diabetes Association in June 2008, showed that pioglitazone produced a remarkable reduction (81\%) in conversion of IGT to diabetes in a mean period of 2.6 years, in the US population [10].

Asian Indians show several peculiarities in the clinical profile of diabetes [11] and also in the response to pharmacological intervention for the primary prevention of diabetes [4]. The Indian Diabetes Prevention Programme (IDPP)-1 showed that a low dose of metformin $(500 \mathrm{mg} /$ day $)$ was as effective as lifestyle modification [4]. Combining metformin and lifestyle modification did not have an added benefit.

The ACT NOW study has shown that pioglitazone is a potential agent for the primary prevention of diabetes. Our prevention study in Asian Indians with IGT, concluded in April 2008, shows results which are at variance.

This study, IDPP-2, was started while the IDPP-1 [4] was in progress as a second-phase study of another cohort of participants with IGT who were selected using criteria similar to those used for IDPP-1. As the efficacy of lifestyle modification as a preventive tool is proven [1-3], it was considered ethical to advise all participants selected for the primary prevention of diabetes on lifestyle modification. The objective of IDPP-2 was to find out if by adding pioglitazone, the efficacy of lifestyle modification could be enhanced. The groups received either lifestyle modification plus placebo or lifestyle modification plus pioglitazone, and were followed up for 3 years. The results confirm the finding of IDPP-1 [4] that lifestyle modification reduces the incidence of diabetes compared with the incidence in a control group (by 55\% in 3 years) in the relatively nonobese but insulin-resistant participants, who were Asian Indians with IGT. However, the addition of pioglitazone did not enhance the effect. This report suggests the possibility of ethnic differences in the action of pharmacological agents used to prevent diabetes.

\section{Methods}

Sample size It was assumed that the cumulative incidence of diabetes in 3 years would be $40 \%$ in the control group with lifestyle modification and placebo and $25 \%$ in the group receiving lifestyle modification and pioglitazone. The sample sizes required in each of the two groups were 165 with a type 1 error of $5 \%$, with $80 \%$ power. Higher numbers were recruited (204 in group A and 203 in group B) to allow for drop out. The intention-to-treat approach was used.

Men and women of 35 to 55 years were selected among employees, and their families, of service organisations such as the railways and electricity board who responded to workplace announcements, and were identified from areas not included in IDPP-1[4]. The institutional ethics committee approved the study protocol. Written informed consent was obtained from the employers and from each participant.

The flow chart (Fig. 1) shows details of enrolment and group assignment, carried out between September 2003 and March 2005. Screening was performed with a $2 \mathrm{~h}$ postglucose test using a test-strip method of capillary glucose measurement (Accu-chek Sensor, Roche Diagnostics, Mannheim, Germany). Participants were selected for screening in groups of 100-150/day from a selected unit. Diagnosis of IGT was confirmed (groups of 25-30 per day) using a standard OGTT within 1 week. During the OGTT, fasting, $30 \mathrm{~min}$ and $2 \mathrm{~h}$ blood samples were collected. WHO criteria for IGT $(2 \mathrm{~h}$ value $\geq 7.8$ to $<11.1 \mathrm{mmol} / \mathrm{l}$ ) and diabetes (fasting $\geq 7.0$ and/or $2 \mathrm{~h} \geq 11.1 \mathrm{mmol} / \mathrm{l}$ ) were used [12]. At the time of the OGTT, details of demography, age, sex, medical history, family history of diabetes, height, weight, waist circumference and percentage of body fat (using the impedance meter Tanita TBF-611 Body Fat Monitor, Syscon Instruments, Bangalore, India), occupation and family income were recorded by standard procedures. BMI was calculated. Blood pressure was recorded and history of hypertension (systolic and/or diastolic BP $\geq 130 / \geq 85 \mathrm{mmHg}$ or receiving treatment) was noted. Participants underwent a 12 lead electrocardiogram to assess the presence of cardiac abnormalities. Those with known coronary artery disease, history of stroke, major Q wave abnormalities, or liver or kidney disorders were excluded.

Participants with persistent IGT were assigned to group A (tablet A) and B (tablet B) in sequential order. They were individually instructed on adherence to lifestyle modification and drug intake and were asked to bring the leftover tablets to the reviews. The bottles were labelled with the individually allotted number and participant's name. The participants and investigators were blinded to the group allocation. All tests were repeated annually. Anthropometry, $\mathrm{BP}$ and postprandial blood glucose were measured during interim visits (6 months). Diabetes, if detected, was confirmed with an OGTT and appropriate drugs were prescribed. All participants completed 36 months of follow-up. Annual OGTT was performed on non-diabetic participants, and diabetic participants receiving treatment had fasting and postprandial glucose measurements. The team members included a physician, three laboratory 
Fig. 1 Details of selection and group allocation of study participants
Non-diabetic individuals selected for screening

(September 2003-March 2005)

$n=6,644$ (men:women, 5,671:973)

Reported for screening

$n=6,589$ (men:women, 5,622:967)

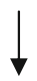

( $2 \mathrm{~h}$ post-glucose capillary glucose test)

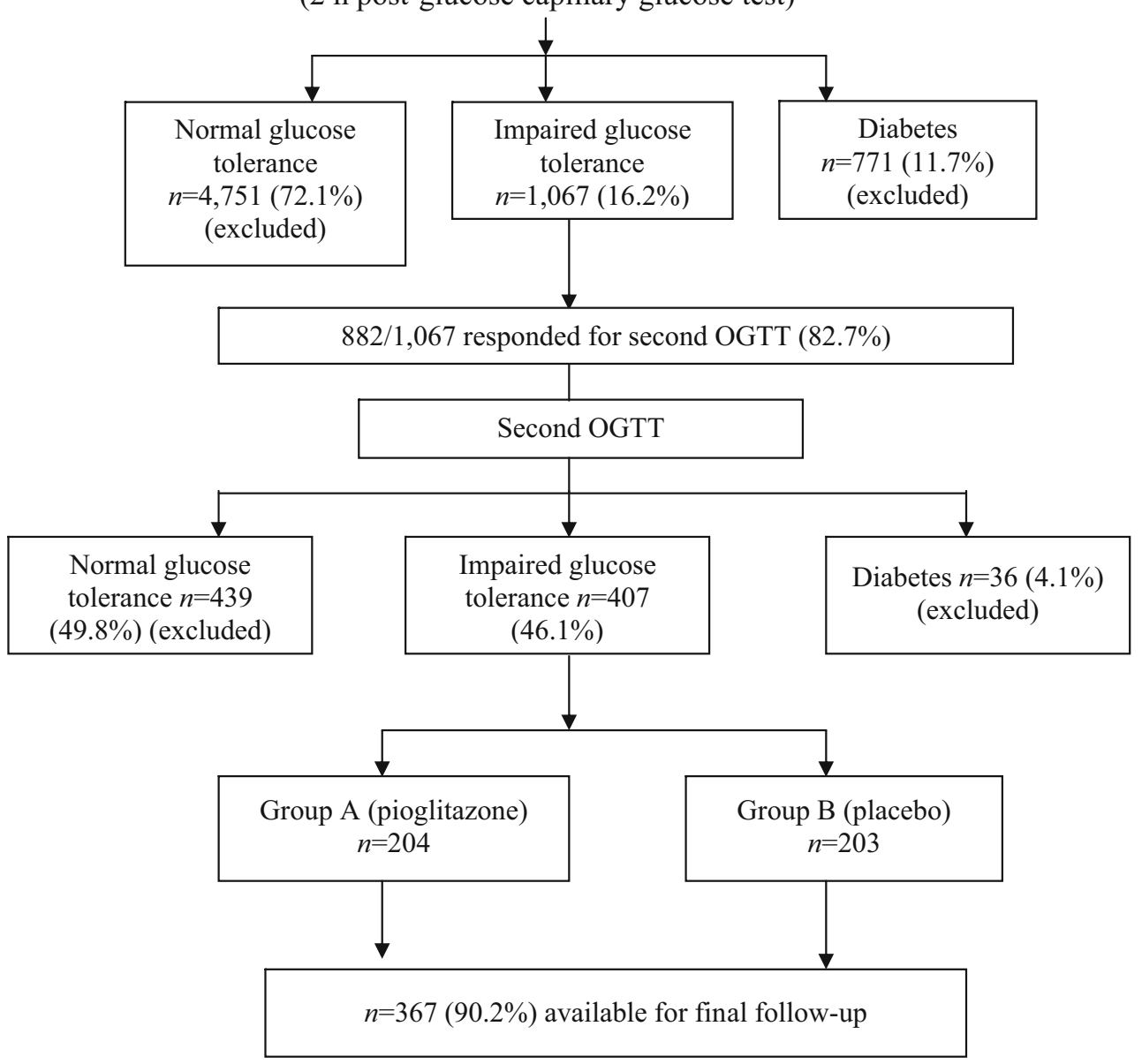

technicians, a dietitian, a social worker and a helper. The measurements were repeated by the same members throughout the study, to eliminate inter-observer variations.

Intervention Lifestyle modification included advice on a healthy diet and regular physical activity. Physical activity assessment included occupational activity, mode of transport to work and leisure time activity. The methods had been validated in previous epidemiological studies $[4,13]$. Participants with strenuous occupational activity and those who either had to walk or cycle for more than $30 \mathrm{~min} /$ day or exercised regularly were asked to continue the activities. All participants who engaged in sedentary or light physical activity, as assessed in the initial interview, were advised to walk briskly everyday for a minimum of $30 \mathrm{~min}$. Scores were given to participants based on adherence. Each participant was advised on diet modification, including reduction in total energy intake and intake of refined carbohydrates and fats, avoidance of sugar, and inclusion of fibre-rich foods.

The starting dose of $15 \mathrm{mg} /$ day was increased to $30 \mathrm{mg} /$ day in all participants at the 6 month interim visit. The dose was increased to $45 \mathrm{mg} /$ day in ten participants in each group. In both groups, more than $60 \%$ complained of giddiness or weakness. Hence, the $30 \mathrm{mg} /$ day dose was continued. The principal investigators, field staff and the study participants were not aware which was the active drug. The code was unblinded at the closure of the study in April 2008 by the advisory committee after reviewing preliminary analysis of the results in March 2008. Tablet A was pioglitazone and tablet B was placebo. 
Advice on lifestyle modification and on regular intake of tablet was given individually at baseline. The instructions were repeated 2 weeks later by telephone or by letter. Thereafter, monthly telephone contact was maintained. Personal sessions were conducted during six monthly visits.

Adherence to diet and physical activity was selfreported, based on weekly pattern, during the personal reviews. Physical activity was assessed by a scoring system and adherence to physical activity was calculated. The proportions of adherent participants were calculated. Drug adherence was assessed by tablet count performed once in 6 months and an average for 3 years was calculated. Participants diagnosed with diabetes or any other illness were referred to their physician.

An international data monitoring committee monitored the conduct of the study. Any serious adverse reactions or events were reviewed and appropriate remedial measures were taken by the internal safety committee, which comprised an administrator and a consultant physician.

Laboratory analysis Blood samples were brought to the laboratory on ice. Plasma glucose (fluoride tube) was measured using the glucose oxidase-peroxidase method. The fasting serum lipid profile was estimated using standard enzymatic procedures, and $\mathrm{HbA}_{1 \mathrm{c}}$ (EDTA sample) by immunoturbidimetry (TINA-QUANT II, Roche Diagnostics). Biochemical assays were performed using the Hitachi 912 autoanalyser (reagents from Roche Diagnostics), with appropriate quality control. Plasma/serum samples for the measurement of other biochemical variables were stored at $-70^{\circ} \mathrm{C}$.

Plasma insulin was measured using a radioimmunoassay kit with a sensitivity of $<24 \mathrm{pmol} / \mathrm{l}$ and intra- and interassay $\mathrm{CV}<10 \%$ (Diasorin, Saluggia, Italy). Insulin resistance was calculated using the homeostasis model assessment for insulin resistance (HOMA-IR) [14]. Beta cell secretory function was calculated as insulinogenic index [15], measured as $30 \mathrm{~min}$ incremental response of insulin/plasma glucose at $30 \mathrm{~min}$.

Statistical analysis Mean and standard deviation are reported for continuous variables. Between-group comparisons were made by Student's $t$ test for normally distributed variables and by Mann-Whitney $U$ test for skewed variables (triacylglycerols). Within-group variations were analysed by the paired $t$ test. The $\chi^{2}$ test or trend $\chi^{2}$ test was used to compare proportions. The cumulative incidence of diabetes in the two groups was estimated using the Kaplan-Meier survival test. The hazard ratio for the primary event in group B vs A (with 95\% CI) was also calculated.

Cox's regression was used to identify the baseline variables that influenced the conversion rate to diabetes. Variables included in the model were: age, sex, study group, BMI, 2 h glucose, HOMA-IR, insulinogenic index, hypertension and family history of diabetes. Interaction of BMI with drug was studied by including BMI $\times$ group in a second model, in place of BMI. A $p$ value $<0.05$ was considered statistically significant. The statistical package Stata version 7.0 (Stata, College station, TX, USA) was used.

\section{Results}

Figure 1 shows the details of sample collection and randomisation. Screening of 6,644 non-diabetic participants identified 407 participants with persistent IGT (i.e. positive on two OGTTs). These individuals were assigned to either group A or group B, and received tablets marked A and B, respectively. At the closure of study, tablet $A$ was revealed to be pioglitazone. There was a male predominance $(86.7 \%)$, but the sex ratio was the same in both groups. The groups had similar age structure, categories of occupation, education and income. At year 3, the overall response rate was $90.2 \%(n=367): 88.7 \%(n=181)$ in the pioglitazone group and $91.6 \%(n=186)$ in the placebo group. In the pioglitazone group, two people died of cardiac arrest, while in the placebo group one person died in a road accident. The causes of death were verified from medical records and death certificates. Participants lost to follow-up numbered 21 in the pioglitazone group and 16 in the placebo group.

All baseline variables were similar in both groups, except for higher values of transaminases in the placebo group (Table 1).

The cumulative incidence of diabetes at 36 months, corrected for the confounding variables such as age, sex, BMI and family history using the Kaplan-Meier survival test, was similar in both groups (pioglitazone $=29.8 \%$ and placebo $=$ $31.6 \%$; unadjusted HR for placebo vs pioglitazone 1.084 [CI $0.753-1.560$ ], $p=0.665$ ); adjusted HR 0.984 [CI $0.672-$ 1.443], $p=0.936$; Fig. 2). Reversal to normoglycaemia occurred in $40.9 \%$ of participants receiving pioglitazone and in $32.3 \%$ receiving placebo; the difference was not statistically significant $\left(\chi^{2} 1.602, p=0.109\right)$. Analysis of the incidence of diabetes in relation to categories of baseline BMI $(<25,25-29$ and $>29 \mathrm{~kg} / \mathrm{m}^{2}$ ) showed a respective distribution of $33.8 \%$, $25.3 \%$ and $43.1 \%$. The differences were statistically nonsignificant (trend $\chi^{2} 6.77, p=0.149$ ).

Cox's proportional hazard model showed that only baseline $2 \mathrm{~h}$ plasma glucose (per mmol) had a significant contribution to the conversion to diabetes with HR 1.014 (95\% CI 1.002-1.026; $\beta=0.014), p=0.024$. The result was similar when either BMI or waist circumference was entered as an independent variable. BMI $\times$ drug interaction was non-significant $(\beta=-0.59, p=0.672)$.

Table 2 shows the between- and within-group variations at year 3. In both groups, mean BP, plasma glucose and 
Table 1 Baseline demographic, anthropometric and biochemical characteristics of the study groups

\begin{tabular}{|c|c|c|}
\hline Characteristic & $\begin{array}{l}\text { Lifestyle } \\
\text { modification } \\
\text { and pioglitazone }\end{array}$ & $\begin{array}{l}\text { Lifestyle } \\
\text { modification } \\
\text { and placebo }\end{array}$ \\
\hline Total $(n)$ (men:women) & $204(178: 26)$ & $203(175: 28)$ \\
\hline Age $(\text { years })^{\mathrm{a}}$ & $45.1 \pm 6.1$ & $45.5 \pm 6.3$ \\
\hline Weight $(\mathrm{kg})^{\mathrm{a}}$ & $69.2 \pm 10.5$ & $68.9 \pm 9.3$ \\
\hline $\operatorname{BMI}\left(\mathrm{kg} / \mathrm{m}^{2}\right)^{\mathrm{a}}$ & $26.0 \pm 3.5$ & $26.2 \pm 3.3$ \\
\hline \multicolumn{3}{|l|}{ Waist circumference $(\mathrm{cm})^{\mathrm{a}}$} \\
\hline Men & $91.2 \pm 8.0$ & $91.3 \pm 7.2$ \\
\hline Women & $89.2 \pm 9.4$ & $89.8 \pm 8.0$ \\
\hline \multicolumn{3}{|l|}{ Body fat $(\%)^{\mathrm{a}}$} \\
\hline Men & $31.4 \pm 5.6$ & $31.2 \pm 5.2$ \\
\hline Women & $42.7 \pm 9.9$ & $46.3 \pm 7.7$ \\
\hline \multicolumn{3}{|l|}{ Blood pressure $(\mathrm{mmHg})^{\mathrm{a}}$} \\
\hline Systolic & $117.7 \pm 10.8$ & $117.9 \pm 11.1$ \\
\hline Diastolic & $75.4 \pm 10.9$ & $75.6 \pm 11.5$ \\
\hline Hypertension, $n(\%)$ & $74(36.3)$ & $71(34.9)$ \\
\hline \multicolumn{3}{|l|}{ Plasma glucose $(\mathrm{mmol} / \mathrm{l})^{\mathrm{a}}$} \\
\hline Fasting & $5.6 \pm 0.7$ & $5.7 \pm 0.6$ \\
\hline $2 \mathrm{~h}$ & $8.9 \pm 0.8$ & $8.9 \pm 0.9$ \\
\hline $\mathrm{HbA}_{1 \mathrm{c}}(\%)^{\mathrm{a}}$ & $5.8 \pm 0.4$ & $5.8 \pm 0.4$ \\
\hline Total cholesterol $(\mathrm{mmol} / \mathrm{l})^{\mathrm{a}}$ & $5.2 \pm 1.0$ & $5.3 \pm 1.1$ \\
\hline Triacylglycerols $(\mathrm{mmol} / \mathrm{l})^{\mathrm{a}}$ & $1.9 \pm 2.8$ & $1.94 \pm 1.4$ \\
\hline SGOT $(\mathrm{U} / 1)^{\mathrm{a}}$ & $26.2 \pm 8.5$ & $28.7 \pm 9.9^{\mathrm{b}}$ \\
\hline SGPT $(U / 1)^{\mathrm{a}}$ & $28.6 \pm 10.7$ & $33.1 \pm 12.2^{\mathrm{b}}$ \\
\hline \multicolumn{3}{|l|}{ Plasma insulin $(\mathrm{pmol} / \mathrm{l})^{\mathrm{a}}$} \\
\hline Fasting & $114.0 \pm 73.8$ & $117.0 \pm 82.8$ \\
\hline $2 \mathrm{~h}$ & $759.6 \pm 394.2$ & $740.4 \pm 391.8$ \\
\hline HOMA-IR ${ }^{\mathrm{a}}$ & $4.7 \pm 3.1$ & $5.0 \pm 3.6$ \\
\hline $\begin{array}{c}\text { Family history of } \\
\text { diabetes } n(\%)\end{array}$ & $117(57.4)$ & $117(57.6)$ \\
\hline Smoking, $n(\%)$ & $37(18.1)$ & $47(23.2)$ \\
\hline
\end{tabular}

${ }^{\mathrm{a}}$ Mean \pm SD

${ }^{\mathrm{b}} p<0.007$ vs pioglitazone group

SGOT, serum glutamic oxaloacetic transaminase; SGPT, serum glutamic pyruvic transaminase

$\mathrm{HbA}_{1 \mathrm{c}}$ were significantly increased and total cholesterol decreased from baseline. Weight gain and change in BMI in 3 years were significantly higher with pioglitazone than with placebo. Baseline mean values of transaminases were higher in the placebo group and decreased significantly at year 3. Elevated enzyme values were seen in four cases at the end of the study (one in the pioglitazone group and three in the placebo group), but the values were lower than $120 \mathrm{U} / 1$ (three times the upper normal limit).

Hypertension became more prevalent with time in both groups: in the pioglitazone group, it increased from 36.5\% $(n=66)$ to $53.6 \%\left(n=97 ; \chi^{2} 10.04, p=0.002\right)$; and in the placebo group, it increased from $34.4 \%(n=64)$ to $58.6 \%$ $\left(n=109 ; \chi^{2} 20.9, p<0.0001\right)$.

At baseline, good dietary practice was reported by 104 participants $(57.5 \%)$ in the pioglitazone group and by 96 $(51.6 \%)$ in the placebo group $\left(\chi^{2} 0.55, p=0.46\right)$. The proportion increased significantly in both groups to $82.3 \%$ $\left(\chi^{2} 31.99, p<0.0001\right)$ and $85 \%\left(\chi^{2} 50.01, p<0.0001\right)$ in the active-treatment and placebo groups, respectively. At baseline, the physical activity level was graded as moderate to high in $48.6 \%$ of the pioglitazone group and $48.9 \%$ of the placebo group. This increased in 3 years to $62 \%\left(\chi^{2} 5.9, p=0.015\right)$ and $66.7 \%\left(\chi^{2} 11.29, p<0.0001\right)$, respectively. Drug adherence (defined as $>80 \%$ drug taken from drug count) was $61.3 \%$ in the pioglitazone group and $60.2 \%$ in the placebo group.

Adverse events In the pioglitazone group, cardiac problems accounted for two deaths and two non-fatal hospital admissions. There were two cases of cardiac disease in the placebo group. More participants in the placebo group than in the pioglitazone group were hospitalised for other reasons such as bone fractures, infectious diseases and treatment for renal stones. Of the four participants with elevated transaminases, three were in the placebo group. None of these individuals had values greater than $120 \mathrm{U} / 1$ (Table 3).

\section{Discussion}

In this study, pioglitazone did not enhance the effectiveness of lifestyle modification in reducing the conversion of IGT to diabetes in Asian Indians. This was in contrast to reports that pioglitazone [9], troglitazone $[6,8]$ and rosiglitazone [7] are highly effective preventive agents in different populations. Troglitazone was found to be highly effective in reducing the incidence of diabetes in individuals with

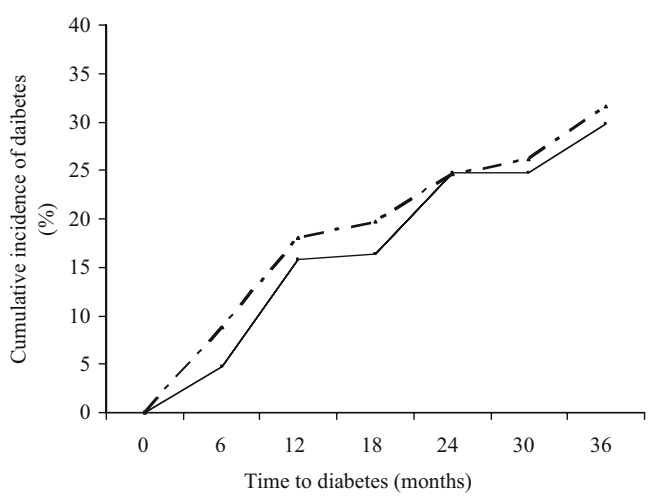

Fig. 2 Cumulative incidence of diabetes in the study groups estimated using the Kaplan-Meier survival test. The incidences were not significantly different: unadjusted HR 1.084 (95\% CI $0.753-1.560)$, $p=0.665$; adjusted HR 0.984 (95\% CI $0.672-1.443$ ), $p=0.936$. The solid line represents the pioglitazone group and the broken line represents the placebo group 
Table 2 Changes in clinical and biochemical variables from baseline to the end of year 3

\begin{tabular}{|c|c|c|c|c|c|c|}
\hline \multirow[t]{3}{*}{ Characteristic } & \multicolumn{4}{|c|}{ Between-group variation } & \multirow{2}{*}{\multicolumn{2}{|c|}{$\begin{array}{l}\text { Within-group variation } \\
\text { Change from year } 3 \text { to baseline }\end{array}$}} \\
\hline & \multicolumn{2}{|l|}{ Baseline } & \multicolumn{2}{|l|}{ Year 3} & & \\
\hline & $\begin{array}{l}\text { Lifestyle } \\
\text { modification } \\
\text { and pioglitazone }\end{array}$ & $\begin{array}{l}\text { Lifestyle } \\
\text { modification } \\
\text { and placebo }\end{array}$ & $\begin{array}{l}\text { Lifestyle } \\
\text { modification } \\
\text { and pioglitazone }\end{array}$ & $\begin{array}{l}\text { Lifestyle } \\
\text { modification } \\
\text { and placebo }\end{array}$ & $\begin{array}{l}\text { Lifestyle } \\
\text { modification } \\
\text { and pioglitazone }\end{array}$ & $\begin{array}{l}\text { Lifestyle } \\
\text { modification } \\
\text { and placebo }\end{array}$ \\
\hline Total $n$ (men:women) & $181(158: 23)$ & $186(164: 22)$ & $181(158: 23)$ & $186(164: 22)$ & $181(158: 23)$ & $186(164: 22)$ \\
\hline Age (years) ${ }^{\mathrm{a}}$ & $44.9 \pm 5.9$ & $45.5 \pm 6.4$ & - & - & - & - \\
\hline Weight $(\mathrm{kg})^{\mathrm{a}}$ & $68.9 \pm 10.2$ & $68.7 \pm 9.1$ & $69.7 \pm 10.1$ & $68.3 \pm 9.0$ & $0.68 \pm 3.0$ & $\begin{array}{l}-0.40 \pm 2.4 \\
p=0.000^{\mathrm{b}}\end{array}$ \\
\hline BMI $\left(\mathrm{kg} / \mathrm{m}^{2}\right)^{\mathrm{a}}$ & $25.9 \pm 3.4$ & $26.0 \pm 3.1$ & $26.2 \pm 3.5$ & $25.9 \pm 3.2$ & $0.28 \pm 1.1$ & $\begin{array}{l}-0.14 \pm 0.9 \\
p=0.000^{\mathrm{b}}\end{array}$ \\
\hline \multicolumn{7}{|l|}{ Waist circumference $(\mathrm{cm})^{\mathrm{a}}$} \\
\hline Men & $91.2 \pm 7.9$ & $91.2 \pm 7.2$ & $90.8 \pm 7.9$ & $90.1 \pm 7.2$ & $-0.39 \pm 3.9$ & $-1.16 \pm 3.3$ \\
\hline Women & $88.9 \pm 9.1$ & $89.0 \pm 8.1$ & $88.8 \pm 8.0$ & $88.5 \pm 9.1$ & $-0.17 \pm 3.7$ & $-0.50 \pm 5.0$ \\
\hline \multicolumn{7}{|l|}{ Body fat $(\%)^{\mathrm{a}}$} \\
\hline Men & $31.5 \pm 5.6$ & $31.2 \pm 5.3$ & $31.7 \pm 6.0$ & $31.2 \pm 5.6$ & $0.27 \pm 3.8$ & $0.001 \pm 3.3$ \\
\hline Women & $41.9 \pm 9.7$ & $45.9 \pm 7.8$ & $43.9 \pm 10.4$ & $44.7 \pm 6.6$ & $1.9 \pm 5.9$ & $-1.18 \pm 4.2$ \\
\hline \multicolumn{7}{|l|}{ Blood pressure $(\mathrm{mmHg})^{\mathrm{a}}$} \\
\hline Systolic & $117.8 \pm 10.6$ & $118.1 \pm 10.9$ & $\begin{array}{l}122.2 \pm 12.5 \\
p=0.000^{\mathrm{c}}\end{array}$ & $\begin{array}{l}123.6 \pm 12.0 \\
p=0.000^{\mathrm{c}}\end{array}$ & $4.4 \pm 13.2$ & $5.5 \pm 13.2$ \\
\hline Diastolic & $75.3 \pm 10.9$ & $75.5 \pm 11.3$ & $\begin{array}{l}77.3 \pm 7.8 \\
p=0.023^{\mathrm{c}}\end{array}$ & $\begin{array}{l}79.1 \pm 7.8 \\
p=0.000^{\mathrm{c}}, p=0.027^{\mathrm{b}}\end{array}$ & $2.0 \pm 11.7$ & $3.6 \pm 11.4$ \\
\hline \multicolumn{7}{|l|}{ Plasma glucose $(\mathrm{mmol} / \mathrm{l})^{\mathrm{a}}$} \\
\hline Fasting & $5.6 \pm 0.6$ & $5.7 \pm 0.6$ & $\begin{array}{l}5.8 \pm 1.1 \\
p=0.005^{\mathrm{c}}\end{array}$ & $\begin{array}{l}5.9 \pm 1.1 \\
p=0.016^{\mathrm{c}}\end{array}$ & $0.24 \pm 1.1$ & $0.19 \pm 1.0$ \\
\hline $2 \mathrm{~h}$ & $8.8 \pm 0.9$ & $8.9 \pm 0.9$ & $9.2 \pm 3.0$ & $\begin{array}{l}9.5 \pm 2.9 \\
p=0.002^{\mathrm{c}}\end{array}$ & $0.59 \pm 3.0$ & $0.68 \pm 2.6$ \\
\hline $\mathrm{HbA}_{1 \mathrm{c}}(\%)^{\mathrm{a}}$ & $5.7 \pm 0.5$ & $5.8 \pm 0.4$ & $\begin{array}{l}6.2 \pm 0.7 \\
p=0.000^{\mathrm{c}}\end{array}$ & $\begin{array}{l}6.3 \pm 0.8 \\
p=0.000^{\mathrm{c}}\end{array}$ & $0.45 \pm 0.8$ & $0.55 \pm 0.8$ \\
\hline Total cholesterol $(\mathrm{mmol} / \mathrm{l})^{\mathrm{a}}$ & $5.2 \pm 1.0$ & $5.3 \pm 1.1$ & $\begin{array}{l}4.9 \pm 0.8 \\
p=0.006^{\mathrm{c}}\end{array}$ & $\begin{array}{l}4.9 \pm 1.0 \\
p=0.000^{\mathrm{c}}\end{array}$ & $-0.22 \pm 1.0$ & $-0.32 \pm 1.2$ \\
\hline Triacylglycerols $(\mathrm{mmol} / \mathrm{l})^{\mathrm{a}}$ & $1.9 \pm 2.9$ & $1.9 \pm 1.5$ & $1.7 \pm 1.0$ & $1.8 \pm 1.1$ & $-0.25 \pm 2.5$ & $-0.13 \pm 1.4$ \\
\hline $\operatorname{SGOT}(\mathrm{U} / \mathrm{l})^{\mathrm{a}}$ & $26.3 \pm 8.6$ & $\begin{array}{l}28.7 \pm 9.8 \\
p=0.015^{\mathrm{b}}\end{array}$ & $26.7 \pm 9.7$ & $27.9 \pm 12.6$ & $0.37 \pm 10.3$ & $-2.27 \pm 11.7$ \\
\hline $\operatorname{SGPT}(\mathrm{U} /)^{\mathrm{a}}$ & $29.0 \pm 10.8$ & $\begin{array}{l}33.1 \pm 12.2 \\
p=0.001^{\mathrm{b}}\end{array}$ & $\begin{array}{l}26.8 \pm 12.4 \\
p=0.027^{\mathrm{c}}\end{array}$ & $\begin{array}{l}29.0 \pm 15.1 \\
p=0.002^{\mathrm{c}}\end{array}$ & $-0.78 \pm 13.6$ & $-4.1 \pm 14.9$ \\
\hline
\end{tabular}

$p$ values indicating statistical significance (pioglitazone vs placebo) are shown

Between-group comparisons were made by Student's $t$ test for normally distributed variables and by Mann-Whitney $U$ test for skewed variables (triacylglycerols); within-group variations were analysed by the paired Student's $t$ test

${ }^{\mathrm{a}} \mathrm{Mean} \pm \mathrm{SD}$

${ }^{\mathrm{b}}$ Pioglitazone and placebo groups compared using the unpaired Student's $t$ test

${ }^{\mathrm{c}}$ Pioglitazone and placebo groups compared using the paired Student's $t$ test

SGOT, serum glutamic oxaloacetic transaminase; SGPT, serum glutamic pyruvic transaminase

IGT [6] and in women with a history of GDM [8], but these studies had to be terminated prematurely because of hepatic toxicity of the drug. Presently, the safety of rosiglitazone in the prevention or treatment of type 2 diabetes mellitus is being debated as there is a possibility that it increases cardiovascular risk in some individuals $[16,17]$.

Pioglitazone is used widely in India and in other Asian countries for the management of diabetes. This study 
Table 3 Occurrence of adverse events and loss to follow-up during the study

\begin{tabular}{lll}
\hline & Pioglitazone $(n)$ & Placebo $(n)$ \\
\hline Major & 2 & \\
Deaths & 2 & 0 \\
$\quad$ Cardiac arrest & - & - \\
Road accident & & 1 \\
Heart disease & 2 & 1 \\
$\quad$ Requiring hospitalisation & - & 1 \\
$\quad$ Not requiring hospitalisation & 4 & 10 \\
Other major events & & \\
Minor & 15 & 9 \\
Hypoglycaemic symptoms & 2 & 1 \\
Joint pain & 4 & 4 \\
Fracture (traffic accident) & 4 & 1 \\
Fever (typhoid, jaundice, & & \\
$\quad$ chikungunya) & 2 & - \\
Renal stone & - & 2 \\
Hypothyroidism & - & 2 \\
Breathlessness & 1 & 3 \\
Elevated transaminases & \\
$\quad$ SGOT/SGPT) & 23 & 17 \\
Total lost to follow-up & & \\
\hline
\end{tabular}

${ }^{\text {a }}$ Normal value $\leq 40 \mathrm{U} / 1$

SGOT, serum glutamic oxaloacetic transaminase; SGPT, serum glutamic pyruvic transaminase

suggests that pioglitazone does not reduce blood glucose in non-diabetic Asian Indians, but does reduce it in diabetic patients [18]. The insulin-sensitising effect of the drug appears to vary in diabetic and non-diabetic glycaemic ranges.

The participants in ACT NOW were obese, with a mean BMI of $34.3 \mathrm{~kg} / \mathrm{m}^{2}$ in the control and pioglitazone groups [10], whereas the Asian Indian participants in our study had a lower mean BMI of $25.9 \mathrm{~kg} / \mathrm{m}^{2}$. In ACT NOW, the pioglitazone group gained significantly more weight $(3.9 \mathrm{~kg}$ ) than did the placebo group. In the Asian Indians in our study, those taking pioglitazone had a lower degree of weight gain.

Although rosiglitazone reduced incident diabetes in all multi-ethnic populations in the DREAM trial, the effectiveness was lower in Asian Indians (HR 0.60 [95\% CI 0.43-0.84]) than in other populations [7] (HR $<0.40)$. This may be suggestive of a difference in the action of rosiglitazone in the non-diabetic Indian population. Moreover, the effect of rosiglitazone was lower in people with lower BMI [7] $\left(\mathrm{BMI}<28 \mathrm{~kg} / \mathrm{m}^{2}, \mathrm{HR}\right.$ 0.60 [95\% CI 0.48-0.77]; $\mathrm{BMI} \geq 28 \mathrm{~kg} / \mathrm{m}^{2}, \mathrm{HR}<0.35$ ).

Asian Indians are highly insulin resistant compared with other ethnic groups [19]. They show several distinct features, such as higher rates of ATP production [20] and lack of association of intramyocellular lipids with insulin resistance [21]. Genetic differences may also account for their higher susceptibility to insulin resistance and type 2 diabetes mellitus. A few studies in the population have indicated possible differences in the modulating effect of the Pro-Ala polymorphism in the peroxisome proliferator-activated receptor $\gamma$ compared with white populations [22, 23].

Systolic and diastolic BP showed moderate increases in both groups, although there were no significant changes in adiposity. This may have been an age-related change.

In IDPP-1, we reported that lifestyle modification and metformin were equally effective in reducing incident diabetes in Asian Indians and the combination of these interventions did not enhance the benefit [4]. The incidence of diabetes was lower in both groups in the present study when compared with the control group of IDPP-1 [4] (55\% in 3 years), confirming the effectiveness of lifestyle modification in another cohort of individuals with IGT. The addition of pioglitazone did not enhance the effectiveness of lifestyle modification. There may be several reasons for the lack of efficacy of pioglitazone in the Asian population. It is probable that lifestyle modification is maximally effective and the addition of a pharmacological agent does not enhance the benefits. A similar observation was made with metformin in IDPP-1[4]. Also, the dose of pioglitazone, $30 \mathrm{mg}$, may not be optimal in individuals with IGT. However, the observation that pioglitazone doses of $15 \mathrm{mg}$ and $30 \mathrm{mg} /$ day are effective in diabetic patients does not support this theory. Generally, Asian Indians show an adequate response to insulin-sensitising drugs such as metformin at lower doses and as monotherapy both in diabetic patients [18] and for primary prevention [4]. Whether pioglitazone by itself could reduce the incidence of diabetes in this population is not known.

Another possibility, that the action of pioglitazone may differ in relation to BMI, was also ruled out. Baseline BMI showed no significant influence on the incidence of diabetes. Cox's regression analysis also showed that BMI $\times$ drug interaction did not occur. As several peculiarities are noted in the clinical and pharmacokinetic profiles of South Asians with diabetes, it is probable that the lack of efficacy of pioglitazone noted in the present study may reflect an ethnic variation, which may relate to the differences in mechanisms of insulin resistance.

Acknowledgements We are thankful to all the study participants for their cooperation during the tenure of the study. We also thank the members of the International Advisory Committee for their guidance: J. Tuomilehto, Academy Professor, National Public Health Institute, Helsinki, Finland; K. M. Venkat Narayan, Hubert Professor of School of Public Health, Epidemiology Department, Emory University in Atlanta, GA, USA; and P. Zimmet, Director, International Diabetes Institute, Caulfield, VIC, Australia. We also thank the safety committee members: B. Sitaraman, administrative consultant and R. Jain, consultant physician. We thank L. Manjula for helping in recording 
the ECGs, M. Muruganandham for helping with the field work for the study and L. Vijaya for helping with data analysis and secretarial services. The secretarial assistance of A. Bobby is also acknowledged.

Duality of interest The authors declare that there is no duality of interest associated with this manuscript.

\section{References}

1. Tumilehto J, Lindstrom J, Eriksson JG et al (2001) The Finnish Diabetes Prevention Study Group. Prevention of type 2 diabetes mellitus by changes in lifestyle among subjects with impaired glucose tolerance. N Engl J Med 344:1343-1350

2. Pan XR, Li GW, Hu YH et al (1997) Effects of diet and exercise in preventing NIDDM in people with impaired glucose tolerance: the Da Qing IGT and Diabetes Study. Diabetes Care 20:537-544

3. Knowler WC, Barrett-Connor E, Fowler SE et al (2002) Reduction in the incidence of type 2 diabetes with lifestyle intervention or metformin. Diabetes Prevention Program Research Group. N Engl J Med 346:393-403

4. Ramachandran A, Snehalatha C, Mary S, Mukesh B, Baskar AD, Vijay V (2006) The Indian Diabetes Prevention Programme shows that lifestyle modification and metformin prevent type 2 diabetes in Asian Indian subjects with impaired glucose tolerance (IDPP-1). Diabetologia 49:289-297

5. Kosaka K, Noda M, Kuzuya T (2005) Prevention of type 2 diabetes by lifestyle intervention: a Japanese trial in IGT males. Diab Res Clin Pract 67:152-162

6. The Diabetes Prevention Program Research Group (2005) Prevention of type 2 diabetes with troglitazone in the diabetes prevention program. Diabetes 54:1150-1156

7. The DREAM (Diabetes Reduction Assessment with Ramipril and Rosiglitazone Medication) Trial Investigators (2006) Effect of rosiglitazone on the frequency of diabetes in patients with impaired glucose tolerance or impaired fasting glucose: a randomized controlled trial. Lancet 368:1096-1105

8. Buchanan TA, Xiang AH, Peters RK et al (2002) Preservation of pancreatic $\beta$-cell function and prevention of type 2 diabetes by pharmacological treatment of insulin resistance in high-risk Hispanic women. Diabetes 51:2796-2803

9. Xiang AH, Peters RK, Kjos SL et al (2006) Effect of pioglitazone on pancreatic beta-cell function and diabetes risk in Hispanic women with prior gestational diabetes. Diabetes 55:517-522

10. De Fronzo RA (2008) Pioglitazone reduces conversion from impaired glucose tolerance of type 2 diabetes. American Diabetes Association 68th Scientific Sessions: Late Breaking Clinical
Studies presented 9 June. Available as a report by Beals JK from www.medscape.com/viewarticle/575860. Accessed 13 July 2008

11. Ramachandran A, Snehalatha C, Vijay V (2004) Low risk threshold for acquired diabetogenic factors in Asian Indians. Diab Res Clin Pract 65:189-195

12. World Health Organization (1999) Definition, diagnosis and classification of diabetes mellitus and its complications. Part 1: diagnosis and classification of diabetes mellitus $\mathrm{WHO} / \mathrm{NCD} / \mathrm{NCS} /$ 99.2. World Health Organization, Geneva

13. Ramachandran A, Snehalatha C, Baskar AD et al (2004) Temporal changes in prevalence of diabetes and impaired glucose tolerance associated with lifestyle transition occurring in the rural population in India. Diabetologia 47:860-865

14. Mathews DR, Hosker JP, Rudenski AS, Naylor BA, Treacher DR, Turner RL (1985) Homeostasis model assessment: insulin resistance and $\beta$-cell function from fasting plasma glucose and insulin concentrations in man. Diabetologia 28:412-419

15. Byrne CD, Wareham NJ, Brown DC et al (1994) Hypertriglyceridaemia in subjects with normal and abnormal glucose tolerance and suppression of plasma non-esterified fatty acids. Diabetologia 37:889-896

16. Nathan DM, Buse JB, Davidson MB et al (2008) Management of hyperglycaemia in type 2 diabetes mellitus: a consensus algorithm for the initiation and adjustment of therapy. Update regarding the thiazolidinediones. Diabetologia 51:8-11

17. Drazen JM, Morrussey S, Curfman GD (2007) Rosiglitazonecontinued uncertainty about safety. N Engl J Med 357:63-64

18. Ramachandran A, Snehalatha C, Salini J, Vijay V (2004) Use of glimepiride and insulin sensitizers in the treatment of type 2 diabetes - a study in Indians. J Assoc Phys India 52:459-463

19. Snehalatha C, Ramachandran A (1999) Insulin resistance in Asian Indians. Prac Diabetes Int 16:19-22

20. Nair KS, Bigelow ML, Asmann YW et al (2008) Asian Indians have enhanced skeletal muscle mitochondrial capacity to produce ATP in association with severe insulin-resistance. Diabetes 57: $1166-1175$

21. Forouhi NG, Jenkinson G, Thomas EL et al (1999) Relation of triglyceride stores in skeletal muscle cells to central obesity and sensitivity in European and southern Asian men. Diabetologia 42:932-935

22. Radha V, Vimaleswaran KS, Babu HNS et al (2006) Role of genetic polymorphism peroxisome proliferator-activated receptor$\gamma 2$ Pro12Ala on ethnic susceptibility to diabetes in south-Asian and Caucasian subjects. Diabetes Care 29:1046-1051

23. Tai ES, Corella D, Deurenberg-Yap M et al (2004) Differential effects of the C1431T and Pro12Ala PPAR $\gamma$ gene variants on plasma lipids and diabetes risk in an Asian population. J Lipid Res 45:674-685 